\title{
Hancock urged to halt NHS tenders as plug pulled on $\mathrm{f} 65 \mathrm{~m}$ process
}

Following the chaotic collapse of the tendering process for NHS orthodontic services in the West Midlands, the British Dental Association (BDA) and the Association of Dental Groups (ADG) have called on Health and Social Care Secretary Matt Hancock to halt all future procurements, and to outline plans to compensate individual providers who have been left up to $£ 30,000$ out of pocket.

The sector leaders made their call in a letter delivered to the Health Secretary and NHS England Chief Executive Simon Stevens. The process to decide on decade-long contracts, estimated to be worth over $£ 65$ million, was abandoned in December after six chaotic months dogged by administrative failings that had forced the reopening of tenders. Similar moves across other English regions have faced legal challenges.

In some circumstances children who have been waiting for years to start orthodontic treatment on the NHS may face going to the back of the queue when current providers lose their contracts, with existing patients potentially running the risk of long journeys if they do not live near one of the new providers.

Sector leaders say tendering processes place huge burdens on dedicated practices and encourage a 'race to the bottom' to deliver NHS services at the cheapest price.

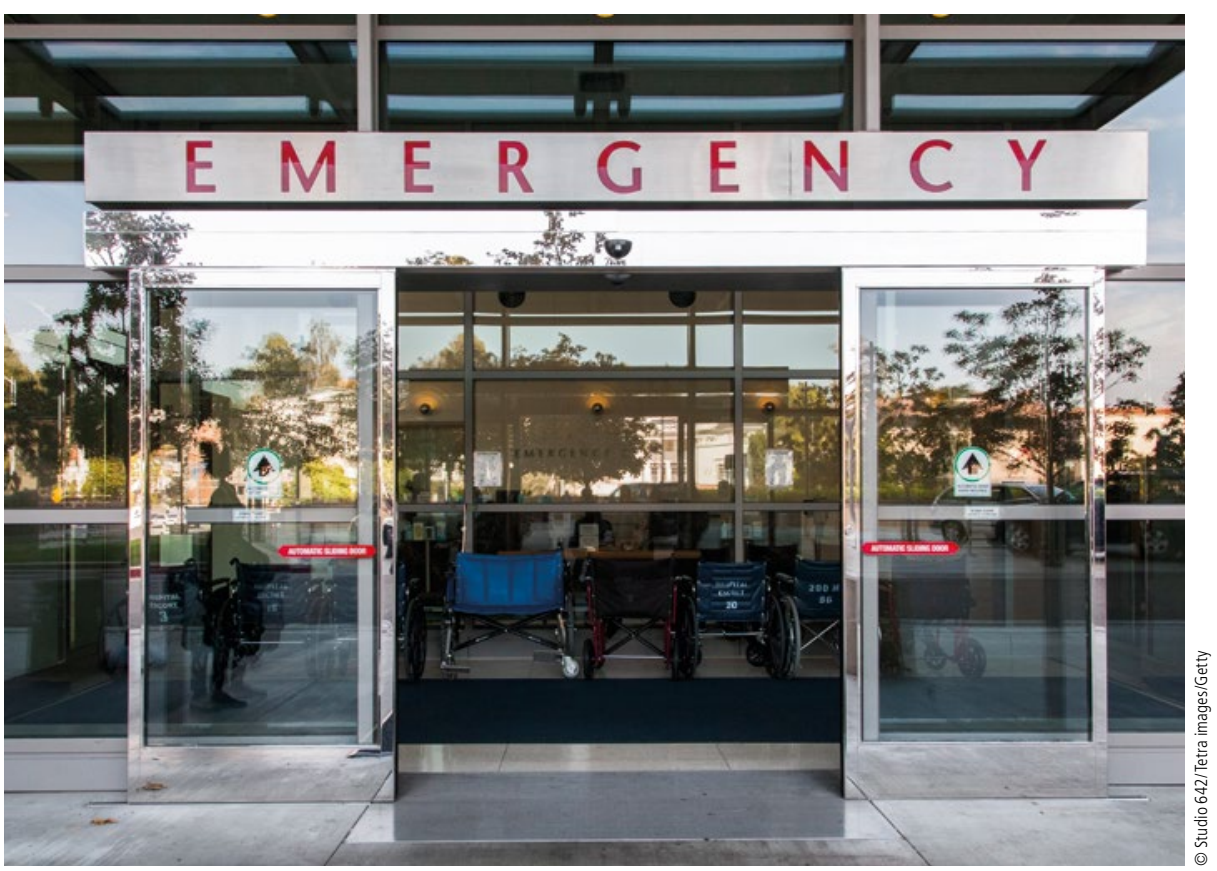

Some contracts in NHS Southern region have already been handed back by successful bidders owing to lack of staff.

The letter outlined the very significant costs facing all providers who participated in tenders who have been left in limbo following the halt to the process. Costs have routinely exceeded $£ 10,000$ to put together a tender, but have reached $£ 30,000$ in some cases.

The BDA had already called on all parties to commit to scrapping tendering for dental services, and for special consideration for the many high performing practices that have lost their contracts during this process.

BDA Chair Mick Armstrong said: 'This fiasco shows why it's time to end this race to the bottom in our NHS. Children could face going to the back of the queue for braces, or switching provider months or years into a course of treatment. Meanwhile practitioners are already facing huge costs and stress in a bidding war to deliver NHS services at the cheapest price'.

\section{SDCEP Dental Companion app now available}

An app to deliver mobile access to evidencebased guidance has been developed by the Scottish Dental Clinical Effectiveness Programme (SDCEP). The Dental Companion joins the popular SDCEP Dental Prescribing app as an alternative convenient way for dental professionals to access SDCEP's clinical guidance. It presents four diverse guidance 'toolkits' based on the following SDCEP publications:

- Prevention and treatment of periodontal diseases in primary care

- Management of dental patients taking anticoagulants or antiplatelet drugs
- Oral health management of patients at risk of medication-related osteonecrosis of the jaw

- Prevention and management of dental caries in children.

Each toolkit includes the key recommendations from the full published guidance, with supporting tools such as flowcharts and links to patient information. The app is also available as a web-based resource for access from any computer for ease of use in the dental surgery.
Launched in August 2019, the Dental Companion has already gained over 4,500 users worldwide, with around 600 individuals accessing the smartphone app and website versions every week. SDCEP will be carrying a more in-depth evaluation of the use of the app via a survey early next year.

The Dental Companion app is available to download free on Google Play or the Apple App Store. The desktop version can be accessed at https://companion.sdcep.org.uk/.

Further information on the work of SDCEP is available at www.sdcep.org.uk. 